\title{
A Study on the Effect of Continuing Education with Digital Technology on Professional Growth and Job Satisfaction of Librarians
}

\author{
Kaijun Yu ${ }^{1}$, Ruiyi Gong ${ }^{1}$, Chunguo Jiang ${ }^{2}$, Shanshan Hu ${ }^{1}$, Longjie Sun ${ }^{1}$, Yu-Zhou Luo ${ }^{3 *}$ \\ ${ }^{1}$ Library, Shanghai University of Medicine \& Health Sciences, Shanghai, CHINA \\ ${ }^{2}$ Library, University of Shanghai for Science and Technology, Shanghai, CHINA \\ ${ }^{3}$ School of Medical Instruments, Shanghai University of Medicine \& Health Sciences, Shanghai, CHINA
}

Received 27 November 2017 - Revised 21 April 2018 - Accepted 10 May 2018

\begin{abstract}
Digital technology and Internet have been combined with modern people's life, and the combination of bit technology with network communication systems largely change people's lifestyles. Along with the popularity of education, the application of digital technology also enhances the basic changes of learning methods and learning contents. To provide quality service, professional librarians are necessary for a library. Accordingly, librarians are the core management element of a library. In the changeable technology era, librarians need constant learning for self-growth through continuing education in order to cope with the changeable environment. Taking librarians of Shanghai University of Medicine \& Health Sciences as the research object, the librarians are proceeded continuing education with digital technology, and the questionnaire is distributed and collected on-site after the continuing education. The research results show that 1.continuing education would significantly and positively affect professional growth, 2.professional growth would remarkably and positively affect job satisfaction, and 3.continuing education would notably and positively affect job satisfaction. With such results, suggestions are proposed, expecting to apply the professional curricula of continuing education with digital technology for the continuous growth of librarians in the changeable era, satisfying the enhancement of core competencies to cope with reader needs under the time and technology changes, and further promoting domestic librarians' professional competence and the development of library business.
\end{abstract}

Keywords: digital technology, library, continuing education, professional growth, job satisfaction

\section{INTRODUCTION}

Digital technology and Internet have been combined with the life of modern people. Carrying mobile phones out, using 3C products of PDA, notebook computers, MP3, and iPod, turning on computers for online chatting, online games, checking e-mails, looking up data, and even online shopping are an important part of modern people's life. Filing tax return, paying bills, and holding video conference through networks have also become the routines of office workers. Regardless the distance of customers, transactions could be completed through e-commerce systems to achieve the objective of rapid, convenient, and saving resources. Networks have replaced a lot of troubled artificial operations and break through the restriction to distance to achieve the borderless information transmission. The combination of bit technology with network communication systems largely changes people's lifestyles. When the society develops to certain degree, people would enhance the concerns about education and expectation. The popularity of education and the application of digital technology also facilitate the basic changes of learning methods and learning contents to focus on education quality.

(C) 2018 by the authors; licensee Modestum Ltd., UK. This article is an open access article distributed under the terms and conditions of the Creative Commons Attribution License (http://creativecommons.org/licenses/by/4.0/).

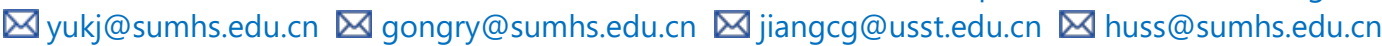




\section{Contribution of this paper to the literature}

- A school should provide subsidies and resources, as regulated, for librarians, according to individual needs, selecting proper lessons for continuing education and contacting the application of digital technology to achieve the professional growth and reserve talents.

- The network learning communication platform could be established with digital technology for librarians recording the learning opinions and experience exchange so as to enhance librarians' professional growth.

- The participation in continuing education with digital technology is listed in the evaluation for promotion and position adjustment, and librarians with positive learning should be rewarded and praised.

A library is composed of buildings, collections, readers, and librarians (Racelis, 2018). To provide quality service, a library needs professional librarians who are therefore the core management element of a library. In the changeable technology era, it is necessary for librarians' constant learning and self-growth through continuing education to cope with such a changeable environment. From a traditional library to a digital library and a mobile library, a library continuously changes and makes progress with the evolution of time with technology progress, changes of users' usage behaviors, and transformation of library functions to prove "a library as an organism of growth". For this reason, major learning channels of degree studies, professional credit courses, short-term studies, digital learning, seminars, business related conference, and book clubs could promote librarians' core competencies. Applying professional curricula of such continuing education with digital technology allows librarians continuously growing in the changeable era, satisfies librarians' enhancement of core competencies, and copes with reader needs under the time and technology changes to further promote domestic librarians' professional competence and the development of library business.

\section{LITERATURE REVIEW}

\section{Digital Technology}

Maeng and Lee (2015) indicated that bit technology contained emerging science technologies of Artificial Intelligence (AI), Data Analytics, Cloud Computing, Virtual Reality (VR), Augmented Reality (AR), and Block Chain. Atenas and Havemann (2014) mentioned that the application of high technology became more important with the time progress; the match of tools, materials, and technologies changed impossible into possible. As the idea of "converting atoms into bits" mentioned in Being Digital, it broke traditional thinking of physical production and simulated real space planning with Virtual Reality. Woo (2014) combined bitmap with new product development to prepare the expansion of marketing channels before the release of products. Besides, bit media, with the feature of audio and video, showed a positive impact on product presentation. They were the best proofs of the integration of digital technology. Ibáñez, Serio, Villarán, and Kloos (2014) indicated that technology development provided lots of new materials and new creation topics for education creation, e.g. replacing a brush with a mouse or a graphics table, replacing canvas with screen server, and replacing substantial space with virtual space. The reproducible, editable, and rich image processing largely resulted in visual impact. Digital technology did not simply introduce new tools or media, but also changed the cognition of affairs (Manek, Shenoy, Mohan, \& Venugopal, 2014). With continuous changes of user experience in new-style interactive products, new modes of operation and usage habits were generated. Accordingly, software businesses, with the mature development of hardware technology, provided diverse application software for users perceiving the convenience of such newstyle smart mobile devices by changing the past electronic product operation experience and methods (Rambli, Matcha, \& Sulaiman, 2013).

\section{Continuing Education}

Sanjay (2016) pointed out continuing education, in adult education dictionary, as educational activities in which adults continuously participated after leaving formal education and prolonged to the life. It provided adults with education or educational activities of professional competence after leaving formal schools, i.e. learning activities extending in individual life (Di Serio, Ibáñez, \& Kloos, 2013). Agarwal and Mittal (2014) referred continuing education as learning activities after stopping full-time compulsory education which could be full-time or parttime, occupational or non-occupational learning activities. Izenman (2013) regarded continuing education as primary, intermediate, and higher education opportunities offered by public and private institutions for people at various age levels, including courses of academic, occupational, leisure, and individual development. Bourgonjon et al. (2013) regarded continuing education as planned and systematic learning activities, aiming to have librarians keep new concepts, advance knowledge and technology, update basic education, and prepare for changing work. In this case, the content was not restricted to the positions, but covered the influence on service. MichelaMortara et 
al. (2014) considered that continuing professional education presented the property of career education, was practice oriented, and focused on in-service professional staff; the contents were professional knowledge and skills of professional industries; and, the method contained formal and informal teaching styles, but mainly informal.

Referring to Chen, Tan, and Lo (2016), the following dimensions are proposed for librarians' continuing education in this study.

(1) Job skills: To make changes, a library has to practice trainings to make up inadequate skills, prevent from getting out of date, and have the business operating conform to the trend.

(2) Professional knowledge: With continuing education, librarians could constantly absorb new knowledge, understand the trend of library business, and complement "professional new knowledge" and "job skills" to promote the library operating efficiency and efficacy.

(3) Self-development: The practice of "enriching work" and "expanding work" could be achieved through continuing education so that librarians could satisfy the need for self-fulfillment and tightly combine librarians career planning with library operating to fully develop the goal management.

\section{Professional Growth}

Ghorbandordinejad and Ahmadabad (2016) mentioned that being professional should constantly accept studies and tests to maintain the professional competence, and "growth" presented the meanings of advance and enhancement. In this case, "professional growth" referred to constantly receiving studies and tests in the execution of professional roles to seek for the continuous progress and growth of professional competence. Molaee and Dortaj (2015) referred professional growth as the constant development to cope with external environment and stress so as to improve professional knowledge and skills. It was not a static concept, but a dynamic process. Alickovic and Subasi (2016) designed a series of processes and activities to enhance personnel's professional knowledge, skills, and attitudes that presented three characteristics of the process with goals, a continuous process, and a systematic process. Jin, Zhao, Chow, and Pecht (2014) indicated that professional growth was not simply the acquisition of facts and knowledge, but a dynamic learning process to understand all affairs and enhance the familiarity to work environment. Cai, Wang, and Chiang (2014) referred to the efforts and willingness for the progress and development of constantly pursuing individual professional competence, skills, and attitudes, covering formal and informal activities for individual positive growth.

Referring to Lee and Hao (2015), the dimensions of administrative competence, professional competence, and professional ethics for librarians' professional growth are utilized in this study.

(1) Administrative competence: The role of a librarian was not simply the information worker. Along with the change of professional roles, a librarian had to cultivate the administrative competence of other relevant affairs, such as policy marketing, public relationship, customer relationship management, and information technology.

(2) Professional competence: An excellent librarian had to present professional competence to complete various services.

(3) Professional ethics: Professional ethics referred to certain professional personnel (e.g. physicians, solicitors, teachers, judges, engineers, accountants, architects) following the moral regulations and responsibilities.

\section{Job Satisfaction}

Hsu (2014) regarded job satisfaction as the attitude or emotional reaction to work, work environment, or the combination of the two. Employees with high job satisfaction would normally present better results, e.g. being actively to match organizational goals, being interested in the job and working harder. An organization therefore should create the situation beneficial to employees' job satisfaction to induce employees achieving goals and performance (Chiu, 2014). Qi, Tian, and Shi (2013) referred job satisfaction to individual awareness of subjective state, originated from positive and pleasant affective reaction at work. Aldhafri, Alkharusi, and Al Ismaili (2015) considered job satisfaction as workers giving positive or negative attitudes or feelings about work or specific layers at work which was the intrinsic psychological state. Young and Wang (2014) indicated that it was the overall subjective value judgment of a worker to the work, working process, or results and the reaction of feeling, attitude, or affection; the satisfaction relied on the gap between the actually acquired value and the expected value; the gap was inversely proportional to satisfaction. Khalid, Khalil, and Nasreen (2014) regarded it as workers' attitude or affective reaction to current positions and the overall feeling and subjective value judgment in the working process that the satisfaction relied on the gap between the actually acquired value and the expected value in specific work environment; and, the smaller gap showed the higher satisfaction. Wang and Han (2015) divided job satisfaction into internal, external, and overall. Internal satisfaction referred to a worker's satisfaction with the value, responsibility, sense of achievement, social status, occupational status, and opportunity to apply abilities induced 
at work. External satisfaction referred to the satisfaction with the salary and promotion acquired at work, the interaction with the supervisors, subordinates, and colleagues, company policies, as well as practice methods. Overall satisfaction indicated the entire internal and external satisfaction. Referring to Tang (2016), job satisfaction is the positive affection and opinions of workers to the entire work that the single dimension is used for measuring job satisfaction in this study.

\section{Hypothesis Derivation}

Maeng and Lee (2015) mentioned that the citizens were positively promoted and encouraged to participate in lifelong learning; especially, staff in public institutions was holding a lifelong learning passport, and there was a complete website management mechanism for public servants' lifelong learning. Libraries also utilized continuing education for enhance the emphasis on professional growth in past years. Sanjay (2016) found out the highly positive correlation between continuing education and professional growth, revealing that the more positive participation in continuing education would assist more in the professional growth. In this case, librarians with more opportunities to receive continuing education would show better professional growth. Seri, Ibáñez, and Kloos (2013) pointed out three major factors in college librarians' continuing education, including the consensus between supervisors and librarians, dissatisfaction with the need for continuing education, and the acquisition of continuing education to enhance professional growth. Chen et al. (2016) indicated that librarians could enhance professional growth with continuing education, and reading books and journals, participating in seminars, and correspondence or air instruction were the common methods. The following hypothesis is therefore proposed in this study.

H1: Continuing education would significantly and positively affect professional growth.

Molaee and Dortaj (2015) studied job satisfaction and professional growth and revealed that participation in professional growth activities, e.g. credit courses, degree courses, or non-credit courses, could enhance the promotion opportunity and remuneration, remarkably enhance satisfaction with knowledge sharing and peer acceptance, and make progress on the control of ability and work environment. In other words, professional growth could enhance job satisfaction. Subasi, Alickovic, and Kevric (2017) pointed out the notable correlation between professional growth opportunities and job satisfaction. People without professional growth opportunities would more easily quit the job that providing professional growth opportunities would enhance job satisfaction and reduce job burnout and turnover rate. Alickovic and Subasi (2016) considered that professional growth could enhance the responsibility and confidence in job as well as stimulate thinking to further engage in study, change, and update knowledge, increase sense of job achievement, and acquire promotion for the status of nursing leaders. Such incentives to work could enhance job satisfaction. Accordingly, the following hypothesis is derived in this study.

H2: Professional growth would remarkably and positively affect job satisfaction.

Lee and Hao (2015) indicated that training contents, teacher quality, and training effectiveness in continuing education showed significantly positive effects on satisfaction. Wang and Han (2015) pointed out the remarkably positive effects of training plan, environment equipment, and training effectiveness in continuing education on satisfaction with value commitment. Uysal and Gunal (2014) stated the notably positive effects of teacher quality, environment equipment, and training effectiveness in continuing education on satisfaction, and continuing education planning and training effectiveness presented significantly positive effects on retention commitment. Tang (2016) indicated that employees with better reaction to continuing education would reflect stronger job satisfaction to further present higher organizational commitment. For this reason, enhancing employees' positive reaction after continuing education and further reinforce the learning effectiveness and professional growth were the keys in promoting the job satisfaction. The following hypothesis is therefore derived in this study.

H3: Continuing education would notably and positively affect job satisfaction.

\section{RESEARCH METHOD DESIGN}

\section{Research Object}

Librarians of Shanghai University of Medicine \& Health Sciences, as the research samples, are proceeded continuing education with digital technology. The questionnaire is distributed and collected on-site after the continuing education. Shanghai University of Medicine \& Health Sciences, the direct university of Shanghai Municipal Education Commission, was established in May 2015. The library was established at the same time. The head library is located in the south building of Pudong campus, and there are branches in the north building of Pudong campus and Xuhui campus. The library of Shanghai University of Medicine \& Health Sciences insists on the goal of "passing down civilization and wisdom to educate people", focuses on student growth, and constantly expands and innovates with teacher service as the key point. According to "the combination of medical treatment 
Table 1. Analysis of continuing education to professional growth

\begin{tabular}{|c|c|c|c|c|c|c|}
\hline \multirow{3}{*}{$\begin{array}{c}\text { dependent variable } \rightarrow \\
\text { independent variable } \downarrow \\
\text { continuing education }\end{array}$} & \multicolumn{6}{|c|}{ professional growth } \\
\hline & \multicolumn{2}{|c|}{ administrative competence } & \multicolumn{2}{|c|}{ professional competence } & \multicolumn{2}{|c|}{ professional ethics } \\
\hline & Beta & $\mathbf{t}$ & Beta & $\mathbf{t}$ & Beta & $\mathbf{t}$ \\
\hline job skills & 0.172 & $1.816^{\star}$ & 0.163 & $1.722^{\star}$ & 0.177 & $1.849^{*}$ \\
\hline professional knowledge & 0.183 & $1.944^{*}$ & 0.191 & $2.086^{\star \star}$ & 0.158 & $1.683^{*}$ \\
\hline self-development & 0.169 & $1.789^{*}$ & 0.188 & $1.975^{\star}$ & 0.198 & $2.106^{\star *}$ \\
\hline $\mathrm{F}$ & \multicolumn{2}{|c|}{22.431} & \multicolumn{2}{|c|}{28.615} & \multicolumn{2}{|c|}{33.462} \\
\hline significance & \multicolumn{2}{|c|}{$0.000^{\star \star \star \star}$} & \multicolumn{2}{|c|}{$0.000 * * *$} & \multicolumn{2}{|c|}{$0.000^{\star \star \star *}$} \\
\hline R2 & \multicolumn{2}{|c|}{0.233} & \multicolumn{2}{|c|}{0.251} & \multicolumn{2}{|c|}{0.296} \\
\hline adjusted R2 & \multicolumn{2}{|c|}{0.202} & \multicolumn{2}{|c|}{0.227} & \multicolumn{2}{|c|}{0.268} \\
\hline
\end{tabular}

Note: * stands for $p<0.05,{ }^{* *}$ for $p<0.01,{ }^{* * *}$ for $p<0.001$.

Data source: Self-organized in this study

and health, medical treatment and engineer, medical treatment and insurance", the school positively develop, expand, and integrate various resources to establish a characteristic library for the guarantee of teaching and scientific research as well as the fulfillment of an applied, characteristic, and international medical college.

\section{Analysis Method}

Regression analysis is applied to understand the relationship among continuing education, professional growth, and job satisfaction.

\section{ANALYSIS RESULT}

\section{Reliability and Validity Analysis}

With factor analysis, three factors of "job skills" (eigenvalue=3.162, $a=0.83$ ), "professional knowledge" (eigenvalue=2.738, $\mathrm{a}=0.81$ ), and "self-development" (eigenvalue=2.334, $\mathrm{a}=0.87$ ) are extracted for continuing education. The common cumulative variance explained achieves $78.671 \%$.

Professional growth, with factor analysis, are extracted three factors of "administrative competence" (eigenvalue=2.773, $\mathrm{a}=0.82$ ), "professional competence" (eigenvalue=2.125, $\mathrm{a}=0.84$ ), and "professional ethics" (eigenvalue $=1.834, a=0.80$ ). The common cumulative variance explained reaches $80.266 \%$.

With factor analysis, job satisfaction shows the eigenvalue $=4.127, \mathrm{a}=0.89$, and the common cumulative variance explained achieves $83.221 \%$.

\section{Correlation Analysis of Continuing Education and Professional Growth}

To test H1, Table 1 reveals that job skills $\left(\mathrm{t}=1.816^{*}\right)$, professional knowledge $\left(\mathrm{t}=1.944^{*}\right)$, and self-development $\left(\mathrm{t}=1.789^{*}\right)$ present significant effects on administrative competence; job skills $\left(\mathrm{t}=1.722^{*}\right)$, professional knowledge $\left(\mathrm{t}=2.086^{* *}\right)$, and self-development $\left(\mathrm{t}=1.975^{*}\right)$ show remarkable effects on professional competence; and, job skills $\left(\mathrm{t}=1.849^{*}\right)$, professional knowledge $\left(\mathrm{t}=1.683^{*}\right)$, and self-development $\left(\mathrm{t}=2.106^{* *}\right)$ appear notable effects on professional ethics. $\mathrm{H} 1$ is therefore supported.

\section{Correlation Analysis of Professional Growth and Job Satisfaction}

To test H2, Table 2 shows remarkable effects of administrative competence $\left(\mathrm{t}=2.231^{* *}\right)$, professional competence $\left(t=2.134^{* *}\right)$, and professional competence $\left(t=2.327^{* *}\right)$ on job satisfaction that $\mathrm{H} 2$ is supported. 
Table 2. Analysis of continuing education to job satisfaction

\begin{tabular}{|c|c|c|}
\hline dependent variable $\rightarrow$ & \multirow{2}{*}{\multicolumn{2}{|c|}{ job satisfaction }} \\
\hline independent variable $\downarrow$ & & \\
\hline professional growth & Beta & $\mathbf{t}$ \\
\hline administrative competence & 0.212 & $2.231^{\star *}$ \\
\hline professional competence & 0.206 & $2.134^{\star \star}$ \\
\hline professional ethics & 0.227 & $2.327^{\star \star}$ \\
\hline $\mathrm{F}$ & & \\
\hline significance & & \\
\hline $\mathrm{R} 2$ & & \\
\hline adjusted R2 & & \\
\hline
\end{tabular}

Note: * stands for $p<0.05,{ }^{* *}$ for $p<0.01,{ }^{* * *}$ for $p<0.001$.

Data source: Self-organized in this study

Table 3. Analysis of professional growth to job satisfaction

\begin{tabular}{|c|c|c|}
\hline dependent variable $\rightarrow$ & \multirow{2}{*}{\multicolumn{2}{|c|}{ job satisfaction }} \\
\hline independent variable $\downarrow$ & & \\
\hline continuing education & Beta & $\mathbf{t}$ \\
\hline job skills & 0.219 & $2.289^{\star \star}$ \\
\hline professional knowledge & 0.207 & $2.166^{\star \star}$ \\
\hline self-development & 0.236 & $2.414^{\star \star}$ \\
\hline $\mathrm{F}$ & & \\
\hline significance & & \\
\hline $\mathrm{R} 2$ & & \\
\hline adjusted R2 & & \\
\hline
\end{tabular}

Note: * stands for $p<0.05,{ }^{* *}$ for $p<0.01,{ }^{* * *}$ for $p<0.001$.

Data source: Self-organized in this study

\section{Correlation Analysis of Continuing Education and Job Satisfaction}

To test H3, Table 3 presents notable effects of job skills $\left(t=2.289^{* *}\right)$, professional knowledge $\left(t=2.166^{* *}\right)$, and selfdevelopment $\left(\mathrm{t}=2.414^{* *}\right)$ on job satisfaction that $\mathrm{H} 3$ is supported.

\section{CONCLUSION}

The research results show notable effects of continuing education on professional growth. Since librarians' professional growth is a continuous process, there is not the knowledge of an industry being able to be permanently used, without improving the technology. To provide quality service, a library needs professional librarians. Along with the constant changes of user experience in new-style interactive products, the professional growth of librarians, who should have advanced knowledge or technology, is more important. For this reason, a school should encourage the librarians participating in continuing education with the application of digital technology to enhance the academic attainment. The professional curricula of such digital technology applied continuing education allow librarians keeping up with the time for continuous growth to satisfy reader needs under the time and technology changes. Furthermore, education administration authorities and colleges \& universities, in the lifelong learning era, should commonly plan training courses of library information and administration management with digital technology, make healthy mechanisms for teaching at different classes and training at various levels, encourage librarians' diverse participation, and timely give encouragement and support. In this case, librarians would be enhanced the intention to participate in learning and promote the professional growth.

\section{RECOMMENDATIONS}

Aiming at above research results, the following suggestions are proposed in this study.

1. A library is suggested to actively provide various digital technology applied continuing education related information, announce relevant regulations, and encourage librarians participating in the study. A school should provide subsidies and resources, as regulated, for librarians, according to individual needs, selecting proper lessons for continuing education and contacting the application of digital technology to achieve the professional growth and reserve talents. 
2. A library is an organism for knowledge growth. The knowledge and experience of librarians are the intelligent property of a library that they should be emphasized and shared with each other. Librarians, after receiving continuing education with digital technology, are willing to share with the colleagues. The training reports, handout sharing, or continuing education in the library are the sharing of knowledge learning in a library. Moreover, the network learning communication platform could be established with digital technology for librarians recording the learning opinions and experience exchange so as to enhance librarians' professional growth. It would not simply assist librarians in the promotion of professional growth and job satisfaction, but could further insert more vitality to a library to transform individual knowledge into organizational knowledge through knowledge management to implement the goal of librarians' professional growth and enhance the growth and progress of a library.

3. The human resource management of a library should cover learning policies, which should be regulated in details, including the policy to support continuing education with digital technology, absence for education training courses with digital technology or formal learning activities, provision of financial support, and opportunities for career development. Besides, the participation in continuing education with digital technology is listed in the evaluation for promotion and position adjustment, and librarians with positive learning should be rewarded and praised. Those are powerful incentives. Consequently, definite learning policies are the effective mechanism to facilitate librarians applying digital technology to continuing education. Without them, applying digital technology to continuing education would not be implemented in spite that librarians present strong learning motivation.

\section{REFERENCES}

Agarwal, B., \& Mittal, N. (2014). Text classification using machine learning methods-a survey. In Proceedings of the Second International Conference on Soft Computing for Problem Solving (SocProS 2012), December 28-30, 2012 (pp. 701-709). Springer, New Delhi. https://doi.org/10.1007/978-81-322-1602-5_75

Aldhafri, S., Alkharusi, H., \& Al Ismaili, A. (2015). Predicting English test anxiety: How memorization and critical thinking function? Theory and Practice in Language Studies, 5(6), 1159-1165. https:/ / doi.org/10.17507/tpls.0506.05

Alickovic, E., \& Subasi, A. (2016). Medical decision support system for diagnosis of heart arrhythmia using DWT and random forests classifier. Journal of medical systems, 40(4), 1. https:/ / doi.org/10.1007/s10916-016-04678

Atenas, J., \& Havemann, L. (2014). Questions of quality in repositories of open educational resources: a literature review. Research in Learning Technology, 22(1), 20889. https:/ / doi.org/10.3402/rlt.v22.20889

Bourgonjon, J., Grove, F., Smet, C., Van Looy, J., Soetaert, R., \& Valcke, M. (2013).Acceptance of game-based learning by secondary school teachers. Computers $\mathcal{E}$ Education, 67, 21-35. https:/ / doi.org/10.1016/j.compedu.2013.02.010

Cai, S., Wang, X., \& Chiang, F. K. (2014). A case study of Augmented Reality simulation system application in a chemistry course. Computers in Human Behavior, 37, 31-40. https:/ / doi.org/10.1016/j.chb.2014.04.018

Chen, C.-M., Tan, C.-C., \& Lo, B.-J. (2016). Facilitating English-language learners' oral reading fluency with digital pen technology. Interactive Learning Environments, 24(1), 96-118. https:/ / doi.org/10.1080/10494820.2013.817442

Chiu, H. C. (2014). The Role of Digital Game-Based Learning in University Student's English Learning Strategy, Intrinsic Motivation, Self-Efficacy, Cognitive Load, and Academic Performance.

Di Serio, Á., Ibáñez, M. B., \& Kloos, C. D. (2013). Impact of an augmented reality system on students' motivation for a visual art course. Computers E Education, 68, 586-596. https:/ / doi.org/10.1016/j.compedu.2012.03.002

Ghorbandordinejad, F., \& Ahmadabad, R. M. (2016). Examination of the relationship between autonomy and English achievement as mediated by foreign language classroom anxiety. Journal of Psycholinguistic Research, 45(3), 739-752. https:/ / doi.org/10.1007/s10936-015-9371-5

Hsu, H. Y. (2014). Development and Evaluation of an Instructional Role-playing Game for History Instruction that Integrates Situated Scenarios and Problem-solving Tasks: an Analysis of Acceptance, Flow, Learning Achievement, and Sense of Place.

Ibáñez, M., Serio, Á. D., Villarán, D., \& Kloos, C. D. (2014). Experimenting with electromagnetism using augmented reality: Impact on flow student experience and educational effectiveness. Computers $\mathcal{E}$ Education, 71, 1-13. https:/ / doi.org/10.1016/j.compedu.2013.09.004

Izenman, A. J. (2013). Linear discriminant analysis. In Modern multivariate statistical techniques (pp. 237-280). Springer New York. https://doi.org/10.1007/978-0-387-78189-1_8 
Jin, X., Zhao, M., Chow, T. W., \& Pecht, M. (2014). Motor bearing fault diagnosis using trace ratio linear discriminant analysis. IEEE Transactions on Industrial Electronics, 61(5), 2441-2451. https:/ / doi.org/10.1109/TIE.2013.2273471

Khalid, S., Khalil, T., \& Nasreen, S. (2014).A survey of feature selection and feature extraction techniques in machine learning. In Science and Information Conference (SAI), 2014 (pp. 372-378). IEEE. https:/ / doi.org/10.1109/SAI.2014.6918213

Lee, L. C., \& Hao, K. C. (2015). Designing and Evaluating Digital Game-Based Learning with the ARCS Motivation Model, Humor, and Animation. International Journal of Technology and Human Interaction, 11(2), 80-95. https:// doi.org/10.4018/ijthi.2015040105

Maeng, U., \& Lee S. M. (2015). EFL teachers' behavior of using motivational strategies: The case of teaching in the Korean context. Teaching and Teacher Education, 46, 25-36. https://doi.org/10.1016/j.tate.2014.10.010

Manek, A. S., Shenoy, P. D., Mohan, M. C., \& Venugopal, K. R. (2017). Aspect term extraction for sentiment analysis in large movie reviews using Gini Index feature selection method and SVM classifier. World wide web, 20(2), 135-154. https:/ / doi.org/10.1007/s11280-015-0381-x

MichelaMortara, M., Catalanoa, C. E., Bellotti, F., Fiucci, G., Houry-Panchetti, M., \& Panagiotis, P. (2014). Learning cultural heritage by serious games. Journal of Cultural Heritage, 15(3), 318-325. https:/ / doi.org/10.1016/j.culher.2013.04.004

Molaee, Z., \& Dortaj, F. (2015). Improving L2 Learning: An ARCS Instructional-motivational Approach. Procedia Social and Behavioral Sciences, 171, 1214-1222. https:/ / doi.org/10.1016/j.sbspro.2015.01.234

Qi, Z., Tian, Y., \& Shi, Y. (2013). Robust twin support vector machine for pattern classification. Pattern Recognition, 46(1), 305-316. https://doi.org/10.1016/j.patcog.2012.06.019

Racelis, A. (2018). Library Services for the Poor: Theoretical Framework for Library Social Responsibility. Pedagogical Research, 3(2), 06. https://doi.org/10.20897/pr/90831

Rambli, D., Matcha, W., \& Sulaiman, S. (2013). Fun Learning with AR Alphabet Book for Preschool Children. International Conference on Virtual and Augmented Reality in Education. Procedia Computer Science, 25, 211219. https:/ / doi.org/10.1016/j.procs.2013.11.026

Sanjay, G. (2016). A Comparative Study on Face Recognition using Subspace Analysis. In International Conference on Computer Science and Technology Allies in Research-March (p. 82).

Seri, A., Ibáñez, M., \& Kloos, C. (2013). Impact of an augmented reality system on students' motivation for a visual art course. Computers $\mathcal{E}$ Education, 68, 586-696. https:/ / doi.org/10.1016/j.compedu.2012.03.002

Subasi, A., Alickovic, E., \& Kevric, J. (2017). Diagnosis of Chronic Kidney Disease by Using Random Forest. In CMBEBIH 2017 (pp. 589-594). Springer, Singapore. https:/ / doi.org/10.1007/978-981-10-4166-2_89

Tang, L.-Y. (2016). Formative assessment in oral English classroom and alleviation of speaking apprehension. Theory and Practice in Language Studies, 6(4), 751-756. https:/ / doi.org/10.17507/tpls.0604.12

Uysal, A. K., \& Gunal, S. (2014). The impact of preprocessing on text classification. Information Processing $\mathcal{E}$ Management, 50(1), 104-112. https:/ / doi.org/10.1016/j.ipm.2013.08.006

Wang, W., \& Han, M. (2015). Quantitative analysis of the speech of the teachers and students in high school English classroom-based on information technology-based interaction analysis system. Theory and Practice in Language Studies, 5(10), 2107-2111. https:/ / doi.org/10.17507/tpls.0510.18

Woo, J. C. (2014). Digital Game-Based Learning Supports Student Motivation, Cognitive Success, and Performance Outcomes. Educational Technology \& Society, 17(3), 291-307.

Young, S.-C., \& Wang, Y.-H. (2014). The game embedded CALL system to facilitate English vocabulary acquisition and pronunciation. Journal of Educational Technology E Society, 17(3), 239-251.

\section{http://www.ejmste.com}

